D0I: 10.12957/demetra.2016.22512

\title{
O caso Mulher Hulk: corpo e identidade em quadrinhos
}

\section{The She-Hulk case: body and identity in comics}

Eduardo Oliveira Ribeiro de Souza ${ }^{1}$

Deise Miranda Vianna ${ }^{2,3}$

\footnotetext{
${ }^{1}$ Fundação Oswaldo Cruz-FIOCRUZ, Instituto Oswaldo Cruz. Rio de Janeiro-RJ, Brasil.

2 Universidade Federal do Rio de Janeiro, Instituto de Física. Rio de Janeiro-RJ, Brasil.

Apoio: Instituto Oswaldo Cruz/FIOCRUZ.

Correspondência / Correspondence Eduardo Oliveira Ribeiro de Souza E-mail: eduardo.souza@ioc.fiocruz.br
}

\section{Resumo}

Neste trabalho discute-se sobre a diferença entre o corpo da Mulher Hulk e do Hulk a partir da origem dos dois personagens, procurando encontrar fatores que justifiquem as diferenças entre eles. Além disso, o artigo apresenta o contexto e as possíveis influências da sociedade na concepção destes personagens. Com base em alguns textos sobre corpo, gênero e saúde, buscam-se as relações entre Hulk e sua versão feminina, numa perspectiva feminista. Discute-se, ainda, como a busca do corpo ideal através do uso de anabolizantes e suplementos alimentares pode ser relacionada com a Mulher Hulk. Procura-se iniciar uma reflexão sobre os elementos que caracterizam a versão feminina do Gigante Esmeralda, bem como levar novas questões para futuras discussões e trabalhos.

Palavras-chave: Quadrinhos. Corpo. Gênero. Física. Ensino de Física. Radiação Gama.

\section{Abstract}

This paper presents a discussion about the difference between She-Hulk's and Hulk's bodies. Based on the origin of the two characters, we seek to find factors that justify the differences between them. Additionally, this paper presents the context and the possible influences from society in the design of these characters. Based on some texts about body, genre and health, we discuss the relationship between Hulk and his female version from a feminist perspective. We will discuss, in this paper, how 
the search for the ideal body through the use of anabolic steroids and dietary supplements may be related to She-Hulk. This study aims to initiate a reflection on the characteristics of the female version of Giant Emerald, and to bring new issues for future discussions and research.

Key words: Comic. Body. Genre. Physics. Physic Teaching. Gamma Radiation.

\section{Introdução}

Este trabalho tem como objetivo discutir os diferentes efeitos da radiação gama no corpo de um homem (Hulk) e no corpo de uma mulher (Mulher Hulk), na perspectiva de que o corpo é compreendido como uma construção social, mutável e mutante, suscetível a transformações e intervenções relacionadas com o desenvolvimento científico e tecnológico de cada cultura, leis e modo de produzir significado no cotidiano. ${ }^{1}$ Em meio a discussões sobre os diferentes gêneros e formas como eles se manifestam, surgiu uma questão envolvendo o incrível Hulk e a Mulher Hulk: se eles são super-heróis semelhantes, por que a Mulher Hulk não tem o corpo deformado e monstruoso como do incrível Hulk?

A Mulher Hulk tem um corpo dentro dos padrões estabelecidos pela sociedade, e de peculiar só tem a pele verde, a incrível força, a preservação da consciência e inteligência; e um aumento corporal de acordo com o nível de sua raiva. A origem de Hulk e de seus poderes foi uma exposição direta à radiação gama, que é nociva ao corpo de qualquer ser humano. Os sintomas de altas dosagens de raios gama seriam náuseas, vômitos, dor de cabeça, perda de glóbulos brancos do sangue, perda de cabelo, danos às células nervosas e danos às células que revestem o trato digestivo. ${ }^{2}$ Além disso, reduz a produção de plaquetas no sangue que ajudam na coagulação, provoca leucemia (câncer no sangue), câncer da tireoide, e inúmeros outros cânceres.

Não vamos aqui discutir a possível existência ou não do Hulk. Não é objetivo deste trabalho. Jean Wood Fuller, uma entusiasmada "cobaia" do teste de 1955 da bomba atômica no deserto de Nevada, exclamou que "as mulheres podem suportar o choque e a tensão de uma explosão atômica tão bem quanto os homens". ${ }^{3}$ No entanto, podemos correlacionar os efeitos dos raios gama ao corpo, nos quadrinhos, ao uso de suplementos alimentares e anabolizantes para atingir o padrão corporal estabelecido., ${ }^{1,4}$

a Este trabalho foi desenvolvido como trabalho final da disciplina Corpo, Gênero e Sociedade, do Programa de Pós-Graduação em Ensino em Biociências e Saúde - Instituto Oswaldo Cruz (Fiocruz), 2014. A disciplina discute o corpo, o gênero e a sexualidade como construções sociais e os modos de fazer ciência, relacionando-os ao desenvolvimento científico e tecnológico a partir de análises operadas pelas ciências sociais em contextos específicos. 
O cerne da discussão deste artigo é investigar os fatores que tornam o corpo da Mulher Hulk sexy e atraente e o do Hulk, monstruoso e deformado. Existem explicações dentro da origem de cada um ou é só uma influência da sociedade e dos padrões que ela estabelece?

\section{O Gigante Esmeraldab}

Em maio de 1962, foi publicada a revista The Incredible Hulk \#16 (figura 1), que conta a história de um físico nuclear franzino e tímido, Dr. Robert Bruce Banner. Ele trabalha na Los Diablos Missile Base - uma base militar localizada no deserto no Novo México - na mais poderosa arma criada pelo homem - a incrível Bomba Gama (no original: Gamma Bomb ou G-Bomb). Durante o primeiro teste da bomba, Banner observa um jovem entrar na área restrita dos testes. Para salválo, Banner pede ao seu colega cientista Igor Starskyc que atrase a contagem regressiva enquanto ele tenta tirar o civil em segurança do local.

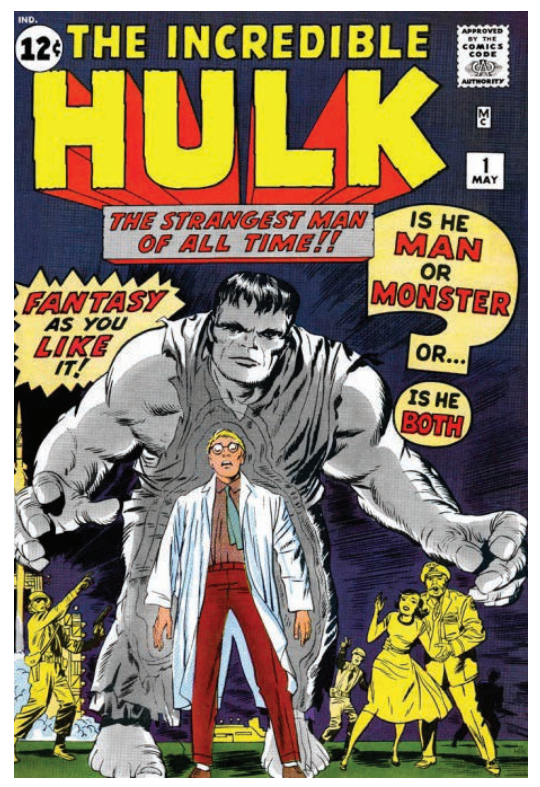

Figura 1. A capa da primeira edição de “The incredible Hulk” (1962)

Fonte: http://en.wikipedia.org/wiki/Hulk_(comics)

b Originalmente, a cor do Hulk era cinza. Stan Lee escolheu uma cor que não sugerisse nenhum grupo étnico em particular. Porém, um problema na impressão da primeira edição deixou a cor de Hulk num tom cada vez mais esverdeado. Na edição seguinte, Hulk já era verde. ${ }^{2,6}$

c Pseudônimo de Igor Drenkov, um espião soviético que deseja roubar os segredos sobre a Bomba Gama. 
Starsky não faz nada a respeito, contando com a morte de Banner na explosão e com isso, ter livre acesso ao projeto da bomba, enquanto os testes estariam suspensos nos Estados Unidos da América. Chegando ao civil, o adolescente Rick Jones, Bruce o joga numa vala de proteção, e antes que conseguisse entrar no mesmo buraco para se proteger, a bomba é detonada. O doutor Banner é irradiado com a radiação gama, e ao invés de ser morto, a radiação faz com que ele se transforme num monstro humanoide de pele cinza, chamado Hulk. ${ }^{6}$

O Incrível Hulk, assim como outros super-heróis, foi criado no contexto da Guerra Fria. Bruce Banner é físico nuclear, carreira científica que ganhou importância após o Projeto Manhattan, ${ }^{\mathrm{d}} \mathrm{e}$ trabalha para os militares, assim como os físicos desse projeto. Mas as semelhanças e relações com a Guerra Fria não param por aí. O teste da Bomba Gama acontece no Novo México, mesmo local onde ocorreu o Experimento Trinity (1945); e a presença de um espião soviético são elementos semelhantes aos acontecimentos da Guerra Fria. Por muitas vezes, Hulk enfrentou inimigos comunistas, mas ainda era perseguido pelos militares americanos. As aventuras também abordavam o horror atômico, do qual a Guerra Fria se alimentava, e ele era sua própria vítima e expressava o arrependimento de muitos cientistas que trabalharam na indústria bélica.

\section{A Mulher Hulk}

A primeira edição da revista The Savage She-Hulk (figura 2) foi publicada em fevereiro de 1980. Agora a protagonista passa a ser Jennifer Walters, advogada e prima de Bruce Banner. Na busca de encontrar uma pessoa confiável para conversar sobre sua transformação, Bruce Banner decide visitar sua prima que mora e advoga em Los Angeles.

Durante a visita, eles são atacados por gângsteres inimigos da advogada, Walters é atingida por um tiro e Bruce Banner consegue salvá-la dos meliantes. Jennifer perde muito sangue e Dr. Banner faz uma transfusão de sangue improvisada até a chegada dos médicos e paramédicos. O sangue de Hulk entra em contato com o sangue de Jennifer Walters, e ela passa a se transformar em Mulher Hulk, quando está em perigo ou com raiva. ${ }^{7}$

d Projeto Manhattan foi a pesquisa que desenvolveu a primeira bomba atômica durante a Segunda Guerra Mundial. Alguns historiadores concordam que o início da Guerra Fria se deu com o lançamento das bombas em Hiroshima e Nagasaki. ${ }^{2,8}$ 


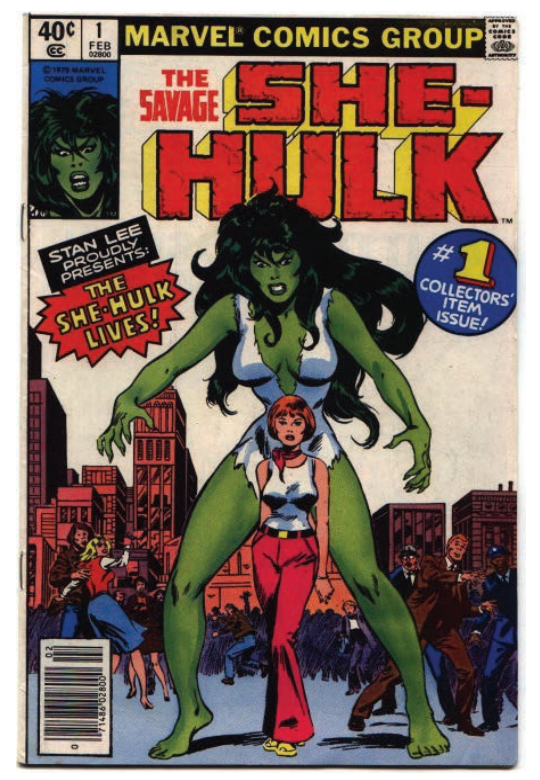

Figura 2. A capa da primeira edição de "The Savage She-Hulk” (1980)

Fonte: http://marvel.wikia.com/wiki/Savage_She-Hulk_Vol_1_1

\section{Discussão}

A origem da Mulher Hulk não é semelhante à do Hulk. Por esse motivo, a pergunta inicial deste trabalho não pode ser respondida pela diferença de efeito da radiação num corpo masculino ou feminino; ou pelo menos não poderemos considerá-la nesse caso. A diferença pode ter se dado apenas porque o corpo dela não teve contato direto com a radiação gama, mas com o sangue de Bruce Banner. Por isso, a exposição direta à radiação gama pode ser a justificativa para o corpo deformado de Hulk, o que não justifica sua versão feminina ter o corpo deformado, só ter ficado verde, maior do que o normal e com todos os poderes dele.

No entanto, a questão da não deformidade do corpo da Mulher Hulk nos leva a novos questionamentos, como por exemplo, o fato de ter sido criada com um corpo escultural não muito musculoso - afinal de contas, a maioria dos leitores de histórias em quadrinhos é homem. Segundo Le Breton ${ }^{9}$ (p. 41):

Na mulher engajada em uma prática intensiva, a ingestão de hormônios masculinos, associada à dietética e aos exercícios, tende a eliminar a feminilidade e a produzir um corpo inédito em sua forma, inapreensível, a não ser pelo corte dos cabelos ou pelas roupas. ${ }^{9}$ 
Tanto homens como mulheres desejam ter corpos ideais, e a Mulher Hulk representa esse ideal corporal, pois ela não é exagerada como o Hulk. A transformação da Mulher Hulk, por exemplo, pode ser relacionada ao uso de anabolizantes e suplementos alimentares. A ingestão de hormônios masculinos, que menciona Le Breton, ${ }^{9}$ pode estar figurada na transfusão do sangue de Bruce Banner para Jennifer Walkers, o que deu origem à versão feminina do Gigante Esmeralda. Muitas pessoas buscam no uso de anabolizantes e suplementos uma satisfação da estética corporal.,5

Por esse motivo, será que se Stan Lee tivesse idealizado o corpo dela exagerado e deformado, ela cairia nas graças dos fãs? Ou será que sua identidade sexual ficaria clara para o leitor? Louro ${ }^{10}$ fala que, para entender o lugar e as relações de homens e mulheres numa sociedade, importa observar não exatamente seus sexos, mas tudo o que se construiu socialmente sobre os sexos. Além disso, as diferentes identidades sexuais são constituídas pelas diferentes formas como vivem nossa sexualidade. A Mulher Hulk é atraente e sexy, e inúmeras vezes suas histórias retratam seus romances e relações sexuais com outros personagens do universo Marvele. Por esse motivo, ela tem uma identidade de gênero e de sexualidade bem construída para os fãs homens.

Recentemente, no postcast Scriptnotes, o roteirista David S. Goyer comentou que a Mulher-Hulk seria como uma atriz pornô feita especialmente para o Hulk. ${ }^{11,12}$ Em resposta, Stan Lee retrucou:

Estávamos pensando em uma nova super-heroína, e estava fascinado pela ideia de um Hulk inteligente. Nunca pensamos em fazê-la como a parceria do Hulk. Só um maluco pensaria nisso. E, por ela ser bonita e cheia de curvas: que super-heroína não é? ?2 $^{2}$

Mas por que as super-heroínas têm que ser bonitas e cheias de curvas? Nossa sociedade tem o que Louro ${ }^{10}$ chama de "normalização da conduta" dos meninos e meninas, onde são produzidos saberes sobre a sexualidade e os corpos, técnicas, táticas e tecnologias que garantam controle ao "governo" e "autogoverno" dos sujeitos. Como já citado, uma mulher muito musculosa tem sua feminilidade perdida, de acordo com os padrões e normas estabelecidos pela sociedade em que vivemos.

Outro questionamento é: por que ela não tem a mesma origem do Hulk? Schienbinger ${ }^{3}$ fala que, na época do Projeto Manhattan, não existiam mulheres trabalhando na bomba atômica. Existiam, sim, mulheres que estavam acompanhando seus maridos e trabalhavam nas "escolas, coordenavam eventos sociais, tinham bebês, cozinhavam, limpavam e criavam uma vida, de certo modo tolerável, na cidade improvisada no deserto (Los Alamos)". ${ }^{2}$ Porém, "no fim da década de 1980, havia três mulheres projetistas de bombas em Los Alamos". ${ }^{2}$ A Mulher Hulk é do início dos

e O Universo Marvel é o cenário fictício criado pela editora Marvel Comics onde se passam as obras produzidas pela editora. O Incrível Hulk e a Mulher Hulk habitam esse universo, assim como o Homem de Ferro, Capitão América, entre outros. 
anos 80, mas os quadrinhos sempre levantaram novidades e revoluções, por que não apresentar uma mulher cientista? Será que ficaria clichê, ela ter uma origem semelhante à do Hulk? Ou a ideia deles era ter uma relação de poder semelhante à da origem de Adão e Eva?

Este estudo buscou iniciar a discussão de gênero que envolve esses dois personagens, não tendo como objetivo encerrar a discussão, mas fomentá-la e desenvolvê-la futuramente.

\section{Considerações finais}

Um fato digno de nota e de futuros estudos sobre a Mulher Hulk é a forma com ela subverte as metalinguagens dos quadrinhos. Ela pula de um quadro para o outro, quebrando a quarta paredef. Ela quebra os quadros para pegar atalhos, ou fala e dá ordem para o narrador, leitor ou roteirista (figura 3).

Os personagens que possuem esse "superpoder" têm a consciência de que seu universo é falso. Com isso, eles são capazes de realizar façanhas que seriam impossíveis dentro do Universo. Eles podem mudar a realidade e muitas vezes têm onisciência dentro do contexto da sua própria realidade falsa ${ }^{13}$.

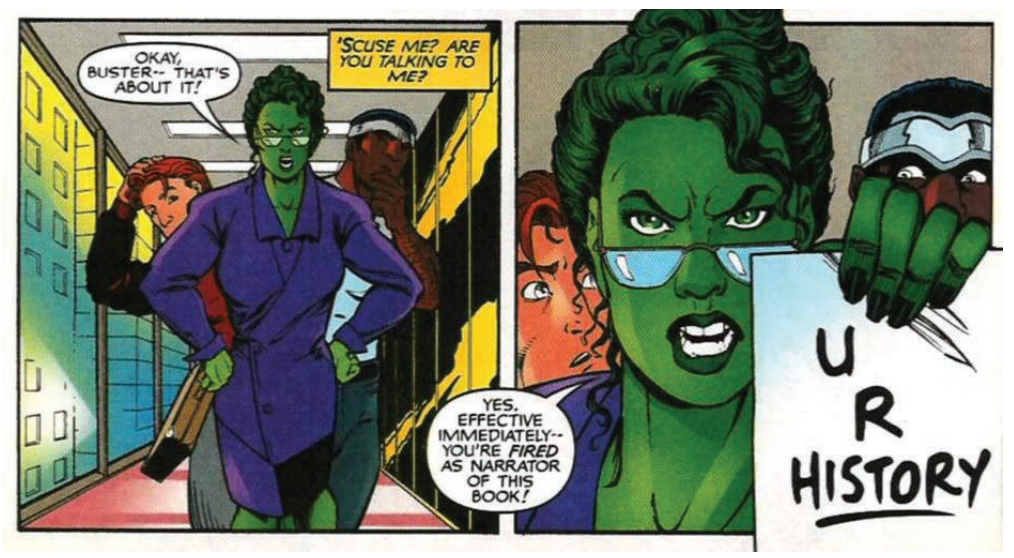

Figura 3. Exemplo de quebra da quarta parede (1989-1994)

Fonte: http://i80.photobucket.com/albums/j182/swiftian/zaius2009a/zaius09d/shehulk1.jpg

f A quarta parede é uma parede imaginária localizada na frente do palco do teatro, ou na tela da televisão e/ ou cinema. 
Na figura acima, Jennifer Walters demite o narrador, porque ele "fala" errado. Os personagens com essa capacidade são considerados loucos ou transgressores da realidade. Por isso, a Mulher Hulk tem esse "poder", o que pode significar duas coisas: (i) uma crítica à falta de voz das mulheres no final dos anos 70 e no início dos anos 80; (ii) ou uma crítica ao lugar-comum, que diz que as mulheres se metem em tudo. Isto é um objeto de estudo interessante para discutir, mas ficará para um próximo trabalho.

\section{Agradecimentos}

Aos professores Eliane Vargas, Francisco Romão e Lucia de la Rocque, por proporcionarem grandes reflexões durante a disciplina "Corpo, gênero e sociedade: aportes para a pesquisa social”, e por motivarem a publicação deste artigo.

\section{Referências}

1. Paixão JA, Lopes MF. Alterações corporais como fenômeno estético e identitário entre universitárias. Sáude Debate 2014; 38(101):267-276.

2. Weinberg R, Gresh L. A ciência dos super-heróis. Rio de Janeiro: Ediouro; 2005.

3. Schienbinger L. O feminismo mudou a ciência? Bauru: Ed. EDUSC; 2001.

4. Iriart JAB, Chaves JC, Orleans GR. Culto ao corpo e uso de anabolizantes entre praticantes de musculação. Cad. Saúde Pública 2009; 25(4):773-782.

5. Silva LSMF, Moreau RLM. Uso de esteróides anabólicos androgênicos por praticantes de musculação de grandes academias da cidade de São Paulo. Rev. Bras. Ciênc. Farm. 2003; 39(3):327-333.

6. Hulk incredible. Marvel Wikia [Internet]. [acesso em: 8 jun. 2014]. Disponível em: http://marvel. wikia.com/Incredible_Hulk_Vol_1_1

7. Savage She-Hulk. Marvel Wikia [Internet]. [acesso em: 6 jun. 2014]. Disponível em: http://marvel. wikia.com/Savage_She-Hulk_Vol_1_1.

8. Vilela T. Quadrinhos e guerra fria: gibis retratam o conflito entre EUA e URSS. Uol Educação Pesquisa Escolar [Internet]. [acesso em: 5 jun. 2014]. Disponível em: http://educacao.uol.com.br/disciplinas/ historia/quadrinhos-e-guerra-fria-gibis-retratam-o-conflito-entre-eua-e-urss.htm

9. Le Breton D. Adeus ao corpo. Campinas: Papirus; 2003.

10. Louro GL. Gênero, sexualidade e educação: uma perspectiva pós-estruturalista Petrópolis: Vozes; 1997.

11. O’Neal S. Stan Lee responds to Davis S. Goyer's "She-Hulk is a sex fantasy" theory. A. V. Club [Internet] 22 May 2014. [acesso em: 5 jun. 2014]. Disponível em: http://www.avclub.com/article/ stan-lee-responds-david-s-goyers-she-hulk-sex-fant-204979 
12. Silva B. David S. Goyer compara Mulher-hulk a estrela pornô e recebe resposta de Stan Lee. Omelete [Internet] 22 maio 2014. [Acesso em: 5 jun. 2014]. Disponível em: http://omelete.uol.com. br/quadrinhos/david-s-goyer-compara-mulher-hulk-estrela-porno-e-recebe-resposta-de-stan-lee/\#. U5fc1PldXYE

13. 4th Wall Awareness. Superpowerwiki [Internet]. [Acesso em: 8 jun. 2014]. Disponível em: http:// powerlisting.wikia.com/wiki/4th_Wall_Awareness

Recebido: $15 / 4 / 2016$

Revisado: 02/8/2016

Aceito: 23/8/2016 
